\title{
Ensino Religioso e Relações Étnico-raciais: Reflexões sobre o Currículo Escolar e a Implementação da Lei 10.639/2003 na Educação Pública Estadual no Amapál
}

\author{
Religious Education and Ethnic-racial Relations: Reflections on the School Curriculum and \\ the Implementation of Law 10.639/2003 in the State Public Education in Amapá
}

\author{
Oneide Bobsin² e Elivaldo Serrão Custódio 3
}

RESUMO

O artigo visa discutir o Ensino Religioso e as relações étnico-raciais no Amapá. Buscamos no decorrer deste trabalho analisar os saberes, os valores e as práticas curriculares e pedagógicas na educação pública estadual, confrontando o trato deste componente com a implementação dos artigos 26-A e 79-B da LDBEN (Leis 10.639/2003 e 11.645/2008), bem como o que preconiza as demais legislações amapaenses. $\bigcirc$ trabalho apresenta os resultados de um estudo exploratório de natureza qualitativa que adotou a pesquisa bibliográfica, a análise documental e a entrevista como forma de investigação. $O$ estudo demonstrou que do ponto de vista prático, a relação Ensino Religioso e Relações Étnico Raciais é insuficiente no que diz respeito a uma educação pautada na diversidade e práticas antirracistas.

PALAVRAS-CHAVE: Ensino Religioso. Relações étnico-raciais. Currículo escolar. Educação pública estadual. Amapá.

ABSTRACT

This article aims to discuss religious education and ethno-racial relations in Amapá. We seek in this paper to analyse the knowledge, values and curriculum and pedagogical practices in state public education, comparing the treatment of this component with the implementation of Articles 26-A and 79-B of LDBEN (Law 10,639/2003 and 11,645/2008), as well as advocating the other Amapá legislation. The work it is the result of an exploratory qualitative study which adopted the literature, document analysis and interviews as a means of investigation. The study showed that from a practical point of view, the relationship Religious Education and Racial Ethnic Relations is insufficient with respect to a guided education in diversity and anti-racist practices.

KEYWORDS: Religious education. Ethnic-racial relations. School curriculum. State public education. Amapá.

\footnotetext{
' Recebido em 20/11/2016. Aprovado em 20/01/2016.

2 Professor de Ciências da Religião da Faculdade EST-RS. Email: obobsin@est.edu.br

${ }^{3}$ Doutorando em Teologia pela Faculdade EST-RS. Email: elivaldo.pa@ hotmail.com
} 


\section{Introdução}

Analisar sob uma visão crítica as relações raciais no Brasil foi e tem sido difícil, isto porque o país apresenta uma autoimagem de uma nação racialmente democrática. Para combater e superar manifestações de racismo, preconceito, discriminação e intolerância religiosa, além de propor mudança efetiva comportamental na busca de uma sociedade democrática e plural, como resultado de um processo histórico de lutas, foram apresentadas desde o início do século XXI, novos marcos legais, no tocante à diversidade cultural. Cabe lembrarmos que os novos marcos legais não surgiram do nada. É o resultado de lutas históricas e de pressões do Movimento Negro por uma educação mais inclusiva e não racista (CUSTÓDIO, 2014, p. 18).

Nesse processo de lutas e conquistas, dentre diversos documentos importantes como leis, resoluções, pareceres, diretrizes, ações e programas ${ }^{4}$, destacamos a Lei ${ }^{0}$ 10.639/2003 - que alterou a Lei $n^{\circ}$ 9.394/1996 (e a Lei n ${ }^{\circ}$ 11.645/2008 que acrescentou a obrigatoriedade do Ensino da História e da Cultura Indígena). Tudo isto, constitui elementos norteadores e desencadeadores para possíveis modificações de concepções e práticas educativas no âmbito educacional brasileiro.

Quanto às conquistas do componente curricular Ensino Religioso, cabe destacar que esta se constitui hoje, como área de conhecimento, cuja oferta é obrigatória e de matrícula facultativa nos currículos das escolas públicas do Brasil. Portanto,

O Ensino Religioso, enquanto disciplina enquadra-se no padrão comum a todas as outras áreas do conhecimento, ou seja, tem: objeto de estudo: o fenômeno religioso; conteúdo próprio: conhecimento religioso; tratamento didático: didática do fenômeno religioso; objetivos definidos; metodologia própria; sistema de avaliação; inserção no sistema de ensino (JUNQUEIRA, 2013, p. 40).

\footnotetext{
${ }^{4}$ Ver: criação da Secretaria de Políticas de Promoção da Igualdade Racial (SEPPIR]; Secretaria de Educação Continuada, Alfabetização e Diversidade (SECAD). Entre os planos, programas e ações, ver: Plano Nacional de Promoção da Igualdade Racial (PLANAPIR); Comissão Técnica Nacional de Diversidade, para Assuntos Relacionados à Educação dos Afrodescendentes (CADARA); Núcleos de Estudos Afro-brasileiros (NEAB); Estatuto da Igualdade Racial, entre outros/as.
} 
O Ensino Religioso, garantido no artigo 210, parágrafo $1^{\circ}$, da Constituição Federal de 1988 e no artigo 33, da Lei de Diretrizes e Bases da Educação Nacional (LDBEN) nº 9.394/1996, alterado pela Lei $n^{\circ}$ 9.475/1997, é parte integrante da formação básica do cidadão, sendo assegurado o respeito à diversidade cultural religiosa do Brasil.

Ao proibir o proselitismo religioso, a LDBEN, assegura que o Ensino Religioso não deverá mais ser confundido com educação religiosa, pois a confessionalidade ameaça à justiça religiosa, não promove a diversidade e, além disso, não garante a igualdade ente os grupos religiosos. Assim, faz-se necessário respeitar a diversidade cultural e religiosa brasileira, contemplando todos os segmentos religiosos historicamente rejeitados no processo de escolarização da disciplina.

Sendo a religião uma das expressões da diversidade cultural, a disciplina de Ensino Religioso, ao trabalhar conteúdos consubstanciados sobre as Religiões de Matrizes Africanas, apresenta-se como essencial para a compreensão das várias manifestações de vivências religiosas no contexto escolar, cujo conhecimento deve promover a tolerância e o convívio respeitoso com o diferente e o compromisso político com a equidade social no Brasil (CUSTÓDIO, 2014, p. 23-25).

Diante destas considerações, este trabalho visa discutir sobre o Ensino Religioso e Relações Étnico-raciais no Amapá: reflexões sobre o currículo escolar e a implementação da Lei 10.639/2003 na educação pública estadual no Amapá. A escolha desta temática está relacionada à luta por uma prática de um ensino antirracista nas escolas brasileiras. $\bigcirc$ trabalho trata-se do resultado de um estudo exploratório de natureza qualitativa que adotou a pesquisa bibliográfica, a análise documental e a entrevista como forma de investigação.

O texto é baseado na Dissertação de Mestrado apresentada no ano de 2014 ao Programa de Pós-Graduação em Direito Ambiental e Políticas Públicas da Universidade Federal do Amapá (UNIFAP), bem como fruto de reflexões construídas a partir de discussões no âmbito do Grupo de Pesquisa Currículo, Identidade Religiosa e Práxis Educativa e do Grupo de Pesquisa Identidade do Doutorado em Teologia da Escola Superior de Teologia (Faculdades EST) em São Leopoldo/RS, Brasil.

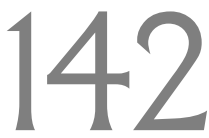




\section{Educação e diversidades: o ensino religioso e as políticas educacionais brasileiras}

A questão da diversidade na educação brasileira se estabeleceu de forma cada vez mais incisiva na agenda das políticas públicas a partir da década de 1990. Um marco para esse debate foi à publicação dos Parâmetros Curriculares Nacionais (Temas Transversais) em 1997. Entretanto, Foster (2004) nos relata que embora a temática transversal Pluralidade Cultural encontrada nos Parâmetros Curriculares Nacionais seja uma forma de superação da discriminação racial, observa na prática a experiência vivenciada pelos sujeitos, no cotidiano escolar, apresenta muito mais processos de manutenção sutil do racismo do que práticas que caminhem na direção de sua ultrapassagem.

Observamos que os Temas Transversais expressam a vontade do poder público de atender genericamente reivindicações históricas do movimento negro brasileiros. Porém, ao diluir os conteúdos em diversas áreas do conhecimento e não definir objetivamente os momentos em que a questão étnico-racial deverá ser incorporada à prática docente, parecem não evitar omissões e silenciamentos. Por isso, os conteúdos afro-brasileiros e africanos continuarão sendo reivindicados na educação básica. Foster $(2004$, p. 10) acredita que,

[...] Os PCN, ao trazem para o âmbito curricular a questão da diversidade e da pluralidade, constituem um ponto de partida para fragilizar as tendências homogeneizadoras que têm imperado na educação nacional, configurando-se como uma das tentativas de estremecer o consenso de uma identidade nacional homogênea, não obstante, nossas discordâncias com relação à natureza da política à qual eles estão atrelados, e à superficialidade com que instigam a pensar certas questões.

Para atender e solucionar alguns problemas educacionais da disciplina de Ensino Religioso, em 1997, através do Fórum Nacional Permanente do Ensino Religioso (FONAPER) foi criado os Parâmetros Curriculares Nacionais para o Ensino Religioso (PCNER) que significou muito mais que um referencial curricular na medida em que determinou a própria constituição da identidade da disciplina escolar. Tornou-se o modelo para a disciplina "Ensino Religioso" na escola pública.

De acordo com Amaral (2003, p. 25-26), trata-se de um libreto de 63 páginas e contém: 
1. Apresentação: Declaração dos propósitos do documento e indicação das partes do texto; 2. Elementos históricos do Ensino Religioso: Visão panorâmica do tema nos 5 séculos de colonização do Brasil. Define a concepção de área de ensino e explicita os objetivos da disciplina; 3. Critérios para a organização e seleção de conteúdos e seus pressupostos didáticos. Além disso, fornece orientação didática sugerindo formas de avaliação; 4. O Ensino Religioso nos ciclos: Elege os conteúdos sugeridos para os quatro ciclos do Ensino Fundamental.

A proposta de organização curricular do Ensino Religioso pelo FONAPER visa requerer um novo planejamento, uma nova seleção de conteúdos e organização, uma nova formação docente com práticas contextualizadas e comprometidas com a diversidade. Embora a divisão efetivada pelos PCNER, através de temáticas traga muitas dificuldades epistemológicas e metodológicas, a organização do currículo do Ensino Religioso traz uma perspectiva de superar as fragmentações e conceber o conhecimento como processo no qual o ser humano é o principal agente.

Verificamos que a diversidade cultural religiosa prevista no Ensino Religioso, como política pública de Estado e de Governo, em que se insere o texto disposto na LDBEN, especialmente, em relação ao Ensino da Cultura e História da África e dos Afrobrasileiros, previstos no artigo 26-A é de caráter obrigatório e permanente, além da necessidade de manifestação dos diversos segmentos religiosos brasileiros [CUSTÓDIO, 2014, p. 86).

Ao tratar sobre a questão pedagógica na escola na perspectiva da diversidade, Gomes (2003) afirma que,

O trato pedagógico da diversidade é algo complexo. Ele exige o reconhecimento da diferença e, ao mesmo tempo, o estabelecimento de padrões de respeito, de ética e a garantia dos direitos sociais [...] Coloca-nos também diante do desafio da mudança de valores, de lógicas e de representações sobre o outro, principalmente, aqueles que fazem parte de grupos historicamente excluídos [GOMES, 2003, p. 74-75].

Neste sentido, refletir sobre educação escolar, e o tratar pedagógico da diversidade, requer não apenas o respeito, mas acima de tudo, o reconhecimento do outro como diferente, ou seja, significa pensar a relação entre o "eu" e o "outro". Se a escola é um espaço sociocultural, discussões sobre as diferentes presenças neste espaço deve fazer

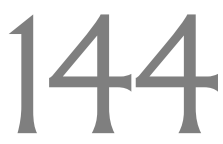


parte da formação, da elaboração curricular, pedagógica e da prática de todos/as envolvidos/as e comprometidos/as com esse processo educacional.

\section{Ensino religioso e relações étnico-raciais no Amapá: saberes, valores e práticas}

Em nossa pesquisa no período de 2013-2014 observamos que a questão da diversidade na escola amapaense parece instaurar uma ação pedagógica insuficiente no que se refere ao trato da diversidade, em especial a questão da diversidade religiosa. Causa-nos preocupação verificar que nas escolas públicas amapaenses, profissionais contratados e/ou efetivos que estão nas salas de aula, à frente dos processos de gestão e de coordenação pedagógica, praticarem abertamente ou de forma sutil, a negação do direito à liberdade religiosa, o desrespeito e a discriminação em relação aos estudantes adeptos de Religiões de Matrizes Africanas e de outras religiões cuja base não é a judaico-cristã.

Neste sentido, é importante relembrarmos que o Parágrafo $1^{\circ}$ do artigo $2^{\circ}$ da Resolução CNE/CP nº 01, de 17 de junho de 2004 que trata das Diretrizes Curriculares Nacionais para a Educação das Relações Étnico-Raciais e para o Ensino de História e Cultura Afro-Brasileira e Africana afirma que:

A educação das relações Étnico-Raciais tem por objetivo a divulgação e produção de conhecimentos, bem como atitudes, posturas e valores que eduquem cidadãos quanto à pluralidade étnico-racial, tornando-os capazes de interagir e de negociar objetivos comuns que garantam, a todos, respeito aos direitos legais e valorização de identidade, na busca da consolidação da democracia brasileira (BRASIL, 2004, p. 31).

E ainda, a Lei $n^{\circ} 10.639 / 2003$, que altera a Lei $n^{\circ} 9.394 / 1996$, que estabelece as Diretrizes Curriculares Nacionais, para incluir no currículo oficial da rede de ensino a obrigatoriedade da temática História e Cultura Afro-Brasileira, apresenta em seu artigo 26A, parágrafo $2^{\circ}$ que "[...] Os conteúdos referentes à História e Cultura Afro-Brasileira serão ministrados no âmbito de todo o currículo escolar [...]", ou seja, não dá mais para se admitir que o espaço do ensino religioso escolar seja um lugar de discussões de religiões cuja base seja somente a judaico-cristã. 
Na perspectiva de mudanças, em 2008, o Governo do Estado do Amapá, principalmente por força das pressões externas do Movimento Negro, sancionou a Lei de $\mathrm{n}^{\circ}$ 1.196/2008. Cabe destacar que somente a partir do ano de 2008, incluiu-se como obrigatório o Ensino da Cultura e História Africana e Afro-brasileira no currículo da educação básica do sistema de ensino estadual, apesar das disposições previstas na Constituição Federal desde 1988.

A lei vem reforçar a aplicabilidade da Lei $n^{\circ}$ 10.639/2003, tornando obrigatório o Ensino da História e Cultura Afro-brasileira e Africana nos estabelecimentos de ensino fundamental e médio, oficial e particular de todo Estado do Amapá.

Cabe destacar também que o Conselho Estadual de Educação do Amapá (CEE/AP) através da Resolução $n^{\circ}$ 51/2012-CEE/AP de 26 de setembro de 2012, estabelece normas complementares às diretrizes curriculares nacionais para a educação das relações étnicoraciais e para o ensino de história e cultura afro-brasileira, africana e indígena no currículo da educação básica e superior do sistema estadual de ensino do estado do Amapá, revogando a Resolução $n^{\circ}$ 075/2009-CEE / AP5 .

A Lei $n^{\circ} 1.196 / 2008$ além de aderir ao texto original da Lei Federal $n^{\circ}$ 10.639/2003, acrescentou as seguintes inovações:

[...] Art. $3^{\circ}$ Caberá ao Conselho de Educação do Estado do Amapá, desenvolver as Diretrizes Curriculares Nacionais instituídas pela Resolução $\mathrm{n}^{\circ} \mathrm{Ol}$, de 17 de junho de 2004, do Conselho Nacional de Educação/ Conselho Pleno/DF dentro do regime de colaboração e de autonomia de entes federativos e seus respectivos sistemas. Art. $4^{\circ} \mathrm{O}$ prazo para implementação do estabelecido no caput do art. $1^{\circ}$ desta lei (torna-se obrigatório o ensino sobre História e Cultura Afro-brasileira), será de $\mathrm{Ol}$ (um) ano, contados da publicação desta Lei. Parágrafo único. A Escola de Administração Pública do Estado disponibilizará curso de especialização para os professores de história da rede de ensino fundamental e médio, visando ao atendimento do ensino estabelecido no caput do art. $1^{\circ}$.

\footnotetext{
${ }^{5}$ A Resolução $n^{\circ}$ 075/2009-CEE/AP também estabelecia normas complementares as diretrizes curriculares nacionais para a educação das relações étnico-raciais e para o ensino de história e cultura afro-brasileira, africana e indígena no currículo da educação básica e superior no sistema estadual de ensino do estado do Amapá.
}

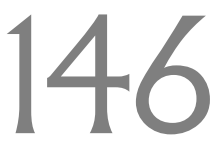


Ao questionarmos ao representante do $\mathrm{NEER}^{6}$ sobre a questão da gestão/ concepção e implementação da Lei Federal n 10.639/2003 e especificamente a Lei Estadual $n^{\circ} 1.196 / 2008$, no que diz respeito às políticas públicas na rede pública do Estado do Amapá, o represente afirmou que:

Bom, a gente vê de forma positiva, eu acho que de certo modo, só o fato de existir a lei, já é positivo, trouxe a discussão a um debate de certa forma, a Secretaria, através do NEER, tem feito, se esforçado suficiente para poder implementar a lei. Nós finalizamos um projeto agora, que foi um curso de especialização para cem professores de história da África e cultura afro-brasileira, nós estamos com a perspectiva de lançar um livro esse ano, que é os projetos que foram feitos nessa especialização, para que permita suporte mais aos professores, nós temos feito sensibilizações nas escolas, não são todas as escolas, não é sempre, tem toda uma limitação, mas a gente faz o esforço, inclusive para estar presente, ah..., mas agora tem que levar em consideração um aspecto que é primordial, que perpassa pela sensibilização do profissional, do professor, e muitas das vezes o professor, ele tem muitas resistências [...] Hoje a gente desenvolve mais ações, de formação continuada, principalmente quando essas escolas nos solicita essa formação, e nós temos um calendário também de ação dentro de algumas escolas, específicas, no ano, e é assim que se tem feito esse trabalho. Agora falta muito, falta muita coisa acontecer, e principalmente em função, da vontade, digamos assim, do profissional [...] [CUSTÓDIO, 2014, p. 146).

Nossa pesquisa ainda revela que embora o representante do NEER tenha informado que cem professores haviam sido contemplados com essa bolsa de estudos, não houve oferta para os profissionais do Ensino Religioso. $\bigcirc$ que confirma a hipótese de que a ausência de capacitação para profissionais desta área do conhecimento no que diz respeito ao tratamento das relações étnico-raciais é preocupante.

Partindo do princípio de identidade e da necessidade de promover ações afirmativas eficazes para combater o racismo, Gomes (2006) propõe uma reforma educacional do Estado e dos/as educadores/as como uma das medidas de política educacional.

A escola tem um papel importante a cumprir nesse debate. Os (as) professores (as) não devem silenciar diante dos preconceitos e discriminações raciais. Antes, devem cumprir o seu papel de educadores (as), construindo práticas pedagógicas e estratégias de promoção da igualdade racial no cotidiano da sala de aula. Para tal é importante saber mais sobre a história e a cultura africana e afro-brasileira, superar opiniões preconceituosas sobre os negros, denunciar o racismo e a

${ }^{6}$ O NEER é o Núcleo de Educação Étnico Racial, órgão ligado a Secretaria de Estado da Educação (SEED), responsável pelas questões étnico raciais das escolas públicas estaduais no Amapá. 
discriminação racial e implementar ações afirmativas voltadas para o povo negro, ou seja, é preciso superar e romper com o mito da democracia racial [GOMES, 2006, p. 60).

Sobre a questão curricular, o Museu Afro-Brasileiro (MAFRO) ${ }^{7}$ através do Projeto de Atuação Pedagógica e Capacitação de Jovens Monitores sobre religiosidade afrobrasileira (2006, p. 5) entende que:

O desafio de aplicar a lei 10.639/03constitui-se, assim, não apenas em incorporar novos conteúdos ao currículo, mas em avaliar como o próprio currículo foi estruturado, a quais interesses corresponde e em que valores civilizatórios é pautado. Esta lei traz a possibilidade de repensar o currículo não só como o que se aprende, mas como se aprende, para quê e para quem é destinada a educação escolar. Desta maneira, torna-se possível pluralizar a educação, adequando-a a sujeitos heterogêneos, levando em conta as diferenças culturais, étnico-raciais, religiosas, de gênero e sexualidade, entre outras, existentes entre eles [...]. A princípio, ser branco ou negro é apenas uma diferença, assim como ser católico ou do candomblé. Porém, uma educação pluricultural deve problematizar como e por que ser branco e cristão significa na sociedade brasileira, ser melhor do que alguém negro e do candomblé [...].

Nos currículos escolares, verificamos que a cultura europeia tem sido valorizada em detrimento da cultura do/a negro/a, apesar deste se constituir em maioria do povo brasileiro. Esse ensino formal, de base branca europeizada, mostra-nos uma imagem que inferioriza o/a negro/a brasileiro/a. Apresenta modelos de negros com estereótipos negativos e através dessa imagem é imposto a esses alunos negros um ideal de ego branco, contribuindo dessa maneira para baixar sua autoestima (CUSTÓDIO, 2014, p. 87).

Segundo Gomes,

A construção de uma educação anti-racista e que respeite a diversidade, baseada na Lei 10.639/03, depara-se com alguns desafios. Dentre eles destacamos: [...] a superação da lógica conteudista no processo de formação de professores(as); a ausência da Lei 10.639/03 nas orientações do Programa Nacional do Livro Didático, a necessidade de maior sistematização e divulgação do pensamento negro brasileiro nos meios acadêmicos e para os profissionais da educação básica; a socialização dos saberes produzidos pela comunidade negra na formação inicial e continuada de professores(as); o diálogo com as questões trazidas pelo Movimento Negro, a articulação entre o conteúdo da lei 10.639/03 e a educação da juventude negra; a inclusão da discussão, estudo e trato ético das religiões de

\footnotetext{
${ }^{7}$ Para maiores informações, ver material completo no site do Museu Afro-Brasileiro (MAFRO). Disponível em: $\quad$ <http:/ / www.mafro.ceao.ufba.br/ userfiles / files / Material\%20do\%2OProfessor\%20-\%20AfroBrasileiro.pdf $>$.
} 
matriz africana na formação de professores(as) da educação básica e na prática das escolas [...] (GOMES, 2007, p. 108).

A LDBEN n 9.394/1996, em seu artigo 26-A, expressa uma das ações públicas que busca minimizar as desigualdades raciais e sociais valendo-se da promoção de uma educação antirracista e antidiscriminatória. Trata-se de uma política educacional controversa, pois exige situar num movimento contraditório e complexo que comporta diferentes direções.

Para Capelo (2003) a questão do fracasso escolar brasileiro está relacionado de um certo modo com o quadro de injustiças sociais apresentadas em nossa sociedade, pois "....] os fazeres e saberes especificamente escolares e pedagógicos não compreendem a complexidade e heterogeneidade sociocultural que só pode manifestar-se na dimensão instituinte do espaço escolar" (CAPELO, 2003, p. 117). Assim a autora sugere que um novo modelo de escolarização que opere rupturas na cultura escolar hegemônica, bem como a fixação de novos conteúdos, programas e exigências.

\section{Considerações finais}

Analisar os saberes, valores, práticas curriculares e pedagógicas da disciplina de Ensino Religioso no Amapá, confrontando o trato desta disciplina com a implementação dos artigos 26-A e 79-B da LDBEN (modificada pelas Leis n 10.639/2003 e 11.645/2008), bem como o que preconiza as demais legislações amapaenses, foi de extrema importância, pois nos possibilitou conhecer como a temática do Ensino Religioso e as Relações Étnicoraciais estão sendo discutidas e/ou gestadas no espaço escolar e quais estratégias e/ou ações estão sendo desenvolvidas para ampliar o diálogo sobre a importância da cultura e identidade negra, do combate ao racismo e da intolerância religiosa no ambiente escolar.

O estudo demonstrou que do ponto de vista prático, a relação Ensino Religioso e relações étnico-raciais é insuficiente no que diz respeito a uma educação pautada na diversidade. Além disso, a prática curricular da disciplina, as orientações pedagógicas e os 
ensinamentos estão muitas vezes, delineados sob o viés cristão, sem qualquer alusão às práticas antirracistas.

Acreditamos que a participação do Estado como um agente facilitador de políticas educacionais que visem à possibilidade de implementação das Diretrizes Curriculares Nacionais para Educação das Relações Étnico-raciais e para o Ensino de História e Cultura Afro-brasileira e Africana, como consta na Lei Federal $n^{\circ} 10.639 / 2003$, Lei Estadual $n^{\circ}$ 1.196/2008, Resolução n 14/2006-CEE/ AP e Resolução n 51/2012-CEE/ AP seja de suma importância para a garantia da cidadania.

Temos consciência de que a partir do conhecimento e da divulgação de temas ligados à cultura africana e afro-brasileira, docentes, discentes e demais profissionais da área da educação, poderão ser capazes de respeitar as diferenças culturais e agir de acordo com a democracia brasileira.

O texto buscou direcionar nossos olhares a respeito de uma educação antirracista por entendermos que a reflexão, que o dialogo é importante para a valorização e preservação da cultura e da identidade negra brasileira, fortalecendo assim a diversidade no espaço escolar. Lembramos que esta discussão cria possibilidades para a superação do racismo presente nas práticas educacionais diárias da educação pública brasileira.

Como proposta e sugestões para discussões e reflexões no espaço escolar no Amapá, acreditamos que promover a capacitação de docentes em eventos que tratem e/ou abordem a disciplina de Ensino Religioso e educação para as Relações Étnico-raciais para a aplicação de conteúdos, onde esses profissionais compreendam, aceitem e valorizem a diversidade religiosa. Assim, acreditamos que essas políticas públicas seriam uma possiblidade de superação do racismo tão enraizado na sociedade brasileira, bem como mais uma ferramenta para conversar com os alunos e alunas sobre religião, diversidade e preconceito.

Entre diversas possibilidades de propostas e sugestões de debates para a capacitação docente, destacamos algumas: a) Conhecer e discutir o Plano Nacional de Implementação das Diretrizes Curriculares Nacionais para Educação das Relações Étnico-raciais e para o Ensino de História e Cultura Afro-brasileira e Africana no espaço escolar; b) Suscitar discussão e reflexão sobre a criação do Plano Estadual de Implementação das Diretrizes 
Curriculares Nacionais para Educação das Relações Étnico-raciais e para o Ensino de História e Cultura Afro-brasileira e Africana; c) Promover debates e discussões sobre a importância da diversidade religiosa e do diálogo inter-religioso; d) Suscitar subsídios pedagógicos sobre religiões de matrizes africanas para uso em sala de aula, bem como para elaboração de conteúdos a serem articulados e desenvolvidos com as outras áreas do conhecimento; entre outras.

\section{Referências Bibliográficas}

AMARAL, Tânia Conceição Iglesias do. Análise dos Parâmetros Curriculares Nacionais para o Ensino Religioso nas Escolas Públicas Brasileiras. 2003. 117f. Dissertação (Mestrado em Educação). Programa de Pós-Graduação em Educação da Universidade Estadual de Maringá, - UEM. Maringá, 2003.

BRASIL. Constituição (1988). Constituição da República Federativa do Brasil. Brasília, 1988. Disponível

em: <http:/ / www.senado.gov.br/sf/legislacao/ const/ con1988/CON1988_30.06.2004/CON19 88.pd>. Acesso em: 18 dez. 2015.

. Lei n. 9.394, de 20 de dezembro de 1996. Brasília, 1996. Estabelece as diretrizes e bases da educação nacional. Disponível em: <http:/ / www.planalto.gov.br/ccivil_03/Leis/L9394.htm>. Acesso em: 18 dez. 2015.

. Lei no 9.475, de 22 de julho de 1997. Brasília, 1997. Dá nova redação ao art. 33 da Lei no 9.394, de 20 de dezembro de 1996, que estabelece as diretrizes e bases da educação nacional. Disponível em: <http:/ / www.planalto.gov.br/ ccivilO3/Leis/ L9475.htm>. Acesso em: 18 dez. 2015.

- Lei $n^{\circ}$ 10.639, de 09 de janeiro de 2003. Brasília, 2003. Instituiu a obrigatoriedade do ensino de História e Cultura Afro-brasileira e Africana no Currículo da Educação Básica. Disponível em: <http:/ / www.planalto.gov.br/ccivilO3/Leis/2003/L10.639.htm>. Acesso em: 18 dez. 2015.

. Lei $n^{\circ} 1.196$ de 19 de fevereiro de 2008. Institui a obrigatoriedade do ensino de História e Cultura Afro-brasileira e Africana no currículo da Educação Básica e dá outras providências. Publicada no Diário Oficial do Estado do Amapá n. 4210 de 14 de março de 2008. Autor Deputado Camilo Capiberibe. 
Conselho Nacional de Educação. Parecer CNE/CP $n^{\circ}$ 003/2004. Diretrizes Curriculares Nacionais para a Educação das Relações Étnico-Raciais e para o Ensino de História e Cultura Afro-brasileira e Africana, 2004.

. Ministério da Educação. Resolução $n^{\circ} 04$ de 13 de julho de 2010. Define Diretrizes Curriculares Nacionais Gerais para a Educação Básica, 2010.

. Ministério da Educação. Resolução $n^{\circ}$ Ol, de 17 de junho de 2004. Institui Diretrizes Curriculares Nacionais para a Educação das Relações Étnico-Raciais e para o Ensino de História e Cultura Afro-Brasileira e Africana, 2004. Disponível em: <http:/ / portal.mec.gov.br/cne/arquivos/pdf/res012004.pdf>. Acesso em: 05 dez. 2011.

Conselho Estadual de Educação do Amapá. Resolução n 14/2006 de 15 de março de 2006. Dispõe sobre a oferta do ensino religioso no nível fundamental, do sistema educacional do Estado do Amapá. Disponível em: <http:// www.gper.com.br/bibliotecadownload.php?arquivold=136>. Acesso em: 28 ago. 2011.

Conselho Estadual de Educação do Amapá. Resolução nº 075/2009-CEE/AP. Estabelece normas complementares as diretrizes curriculares nacionais para a educação das relações étnico raciais e para o ensino de história e cultura afro-brasileira, africana e indígena no currículo da educação básica e superior no sistema estadual de ensino do estado do Amapá. Macapá: 2009.

- Conselho Estadual de Educação do Amapá. Resolução n 51/2012-CEE/AP de 26 de setembro de 2012. Estabelece normas complementares às diretrizes curriculares nacionais para a educação das relações étnico-raciais e para o ensino de história e cultura afro-brasileira, africana e indígena no currículo da educação básica e superior do sistema estadual de ensino do estado do Amapá e revoga a Resolução n 075/2009-CEE/ AP. Macapá: 2012. Disponível em: < http: / / www.gestor.ap.gov.br/ editor / Arquivos / Texto / Gestorc284812d6ff5a82fd63e0376c 004a778Texto.pdf>. Acesso em: 02 nov. 2015.

CAPELO, Maria Regina Clivati. Diversidade sociocultural na escola e a dialética da exclusão inclusão. In : GUSMÃO, Neusa Maria M. de. (Org.). Diversidade, cultura e educação: olhares cruzados. São Paulo: Biruta, 2003.

CUSTÓDIO, Elivaldo Serrão. Políticas públicas e direito ambiental cultural: as religiões de matrizes africanas no currículo escolar no Amapá. Dissertação (Mestrado em Direito Ambiental e Políticas Públicas) - Universidade Federal do Amapá, Macapá, 2014.

FÓRUM NACIONAL PERMANENTE DO ENSINO RELIGIOSO (FONAPER). Parâmetros Curriculares Nacionais: Ensino Religioso. 2a ed. São Paulo: AM Edições, 1997. 
FOSTER, Eugénia Luz da Silva. Racismo e Movimentos Instituintes na Escola. Niterói: 2004. 398f. Tese (Doutorado) - Faculdade de Educação, Universidade Federal de Fluminense, Rio de Janeiro, 2004. Disponível em $<$ http:/ / www.bdtd.ndc.uff.br/tdearquivos/2/TDE-2005-03-

15T14:39:57Z70/Publico/Parte\%201-Tese-Eugenia\%2OFoster.pdf>. Acesso em: 29 out. 2011.

GOMES, Nilma Lino. Educação e diversidade étnico-cultural. In___: RAMOS, Marise Nogueira (et all.). Diversidade na Educação: reflexões e experiências. Brasília: Secretaria da Educação Média e Tecnológica, 2003.

. Alguns termos e conceitos presentes no debate sobre relações raciais no Brasil: uma breve discussão, 2006.

. Diversidade étnico-racial e educação no contexto brasileiro: algumas reflexões. In__ : GOMES, Nilma Lino [Org.). Um olhar além das fronteiras: educação e relações raciais. Belo Horizonte: Autêntica, 2007.

JUNQUEIRA, Sérgio Rogério Azevedo [Coord.). Mapa da produção científica do ensino religioso: no período de 1995 a 2010. Relatório de Pesquisa. Curitiba: PUC, 2013. Disponível em: $<$ http:// www.fonaper.com.br/noticias/140_mapa_do_er_2013__gper.pdf >. Acesso em: 10 abr. 2015.

MUSEU AFRO-BRASILEIRO (MAFRO). Centro de Estudos Afro-orientais da Universidade Federal da Bahia. Setor religiosidade afro-brasileira. Projeto de Atuação Pedagógica e Capacitação de Jovens Monitores. Material do professor. Ano 2006. Disponível em:

$<$ http:/ / www.mafro.ceao.ufba.br/ userfiles/ files/Material\%20do\%20Professor\%20\%20Afro-Brasileiro.pdf>. Acesso em: 18 jul. 2012.

PARÂMETROS CURRICULARES NACIONAIS PARA O ENSINO RELIGIOSO (PCNER). Ensino religioso. Fórum Nacional Permanente do Ensino Religioso. São Paulo: Mundo Mirim, 2009.

SECRETARIA DE ESTADO DA EDUCAÇÃO DO ESTADO DO AMAPÁ (SEED). Plano Curricular da Educação Básica do Estado do Amapá. SEED, Macapá, 2009. Disponível em: < http:/ / www.ceap.br/artigos/ ART27022011132327.pdf >. Acesso em: 10 abr. 2016. 